\title{
Wideband External Pulse Recorded During Cuff Blood Pressure Measurement: A New Technique for Cardiovascular Assessment
}

\author{
Seymour G. Blank ${ }^{1}$. Gary D. James ${ }^{2} \cdot$ Mary J. Roman $^{3}$
}

Received: 6 June 2018 / Accepted: 17 July 2018 / Published online: 27 July 2018

(c) The Author(s) 2018

\begin{abstract}
Introduction The wideband external pulse (WEP) recorded during blood pressure measurement reveals three components (K1, K2, K3). K1 is recorded with cuff pressure (CP) above systolic (SP).

Aim To assess whether the K1 pattern contains information about the functional and structural properties of the cardiovascular system.

Methods WEP analysis, echocardiography, carotid artery (CA) ultrasonography and applanation tonometry were conducted on 178 hypertensives. K1R, a feature of K1, was defined to provide a measure between the arterial incident and backward reflective waves.

Results K1R was strongly correlated to vascular functional and structural parameters compatible with vascular effects of aging and hypertension. ANOVA analysis $(\mathrm{K} 1 \mathrm{R}<0$ vs $\mathrm{K} 1 \mathrm{R}>0)$ showed that $\mathrm{K} 1 \mathrm{R}<0$ participants: (1) were older, shorter, weighed less, had a smaller body surface area; (2) had higher SP, pulse (PP) and mean (MP) pressure, lower heart rate (HR), greater total peripheral resistance (TPR), lower cardiac output (CO), and a stiffer arterial system; (3) had a greater left ventricular (LV) relative wall thickness (LVRWT), carotid artery (CA) relative wall thickness (CARWT), CA far-wall intima-media thickness at end diastole (CIMTd) and CA cross-sectional area (CSA) (all p <0.001). Regressions revealed that age, TPR, SP, gender, and HR predicted K1R $\left(R^{2}=0.64\right)$ and that $P P$ and $K 1 R$ predicted CARWT $\left(R^{2}=0.14\right)$. Logistic regression revealed that age, TPR, $\mathrm{SP}$ and aortic diameter differentiated $\mathrm{K} 1 \mathrm{R}<0$ from $\mathrm{K} 1 \mathrm{R}>0$ (Nagelkerke $\mathrm{R}^{2}=0.77$ ).

Conclusions $\mathrm{K} 1 \mathrm{R}$ is related to vascular functional properties, with suggestive evidence that $\mathrm{K} 1 \mathrm{R}$ is also related to vascular structural properties and perhaps subsequent cardiovascular risk.
\end{abstract}

Keywords Wideband external pulse (WEP) - Arterial pressure · Pulse wave analysis · Blood pressure measurement · Vascular assessment

\section{Introduction}

Just as cardiac function and structure can be inferred from analysis of the electrocardiogram, it has been demonstrated that functional and structural properties of the arterial system can be inferred from the shape of the arterial pressure pulse [1]. The central aortic pressure can be divided into an early and late systolic portion. The early systolic portion

Seymour G. Blank

sblank@citytech.cuny.edu; sddblank@gmail.com

1 Department of Computer Engineering Technology, NYC College of Technology/CUNY, 186 Jay Street V622, Brooklyn, NY 11201, USA

2 Binghamton University, SUNY, Binghamton, NY, USA

3 Weill Cornell Medical College, New York City, NY, USA is determined by left ventricular ejection whereas the late systolic portion is influenced by the degree and timing of pulse wave reflections generated at any vascular impedance mismatch [1]. All of the multiple sources of wave reflection are combined to form an integrated backward wave [2].

We previously reported on a noninvasive technique called wideband external pulse (WEP) recording, which can combine into a single procedure the two major areas of noninvasive analysis of the arterial pressure pulse: blood pressure (BP) measurement and pulse wave analysis [3-10]. Briefly, this technique uses a pressure sensor positioned over the brachial artery and under the distal portion of a BP cuff during standard BP cuff deflation. Three distinct WEP components can be identified: called K1, K2 and K3 (Fig. 1).

$\mathrm{K} 1$ is a low frequency signal which is detectable with cuff pressure (CP) above systolic. $\mathrm{K} 1$ is created by the impact of a 
$\mathbf{a}$

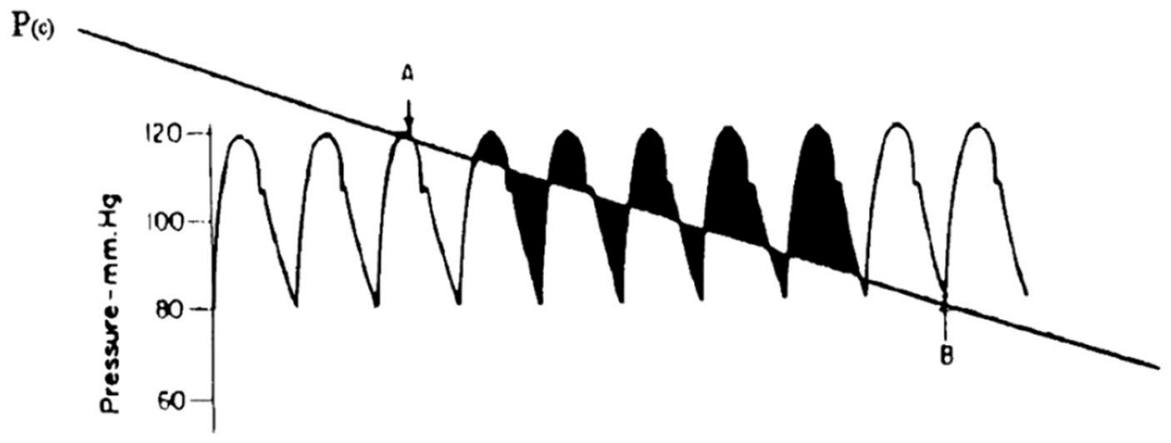

b

$\mathrm{P}(\mathbf{c}) \quad>\mathrm{SP}$

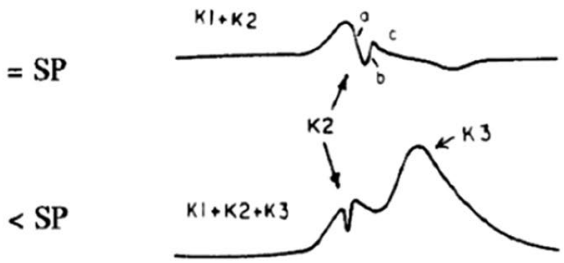

Fig. 1 a Cuff pressure $(\mathrm{Pc})$ being reduced from above systolic pressure (SP, point A) to below diastolic pressure (DP, point B). Shaded areas above cuff pressure represent positive pressure gradients (arterial pressure-cuff pressure) and shaded areas below cuff pressure represent negative pressure gradients. b Changes in the WEP signal as cuff pressure is reduced from above SP to below SP. With Pc $>$ SP,

relatively central arterial pressure pulse against an occluded brachial artery. K1 has a characteristic shape of 3 peaks and 2 troughs. The second trough represents the separation of the systolic and diastolic portions of K1. Although the relative amplitudes of the 2 systolic peaks and one systolic trough vary between subjects, the K1 pattern has been shown to be reproducible across cuff deflations and that within-subject variability of $\mathrm{K} 1$ across multiple cuff deflations is small enough to compute a single $\mathrm{K} 1$ estimate for a single subject [4].

The K2 component visually appears and disappears in conjunction with SP and DP respectively, and is the basis of an objective and accurate method for measuring BP called "K2 Analysis".

The K3 component appears with CP between SP and DP and is the only WEP component visually present with $\mathrm{CP}$ below diastolic.

\subsection{Purpose of Study}

The purpose of this study is to assess whether the shape of the noninvasive $\mathrm{K} 1$ pattern contains information about the functional and structural properties of the arterial system c

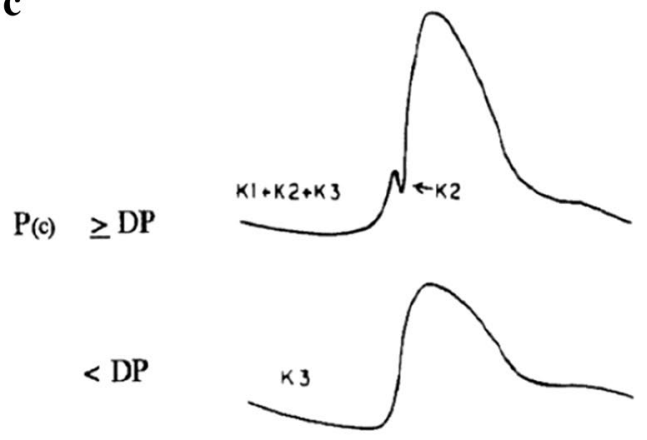

only the $\mathrm{K} 1$ component of WEP is present. With $\mathrm{Pc}=\mathrm{SP}, \mathrm{K} 2$ appears superimposed on the K1 component. With Pc below SP, K3 appears. c Changes in the WEP signal as cuff pressure is reduced from above DP to below DP. With Pc $<$ DP, K2 notch disappears (leaving K3 as the only WEP component) Requires permission from AHA: Hypertension: Blank et. al. Defining DBP in Pregnancy [6]

that is in agreement with known vascular effects of hypertension and aging.

\section{Methods}

\subsection{Subjects}

The study population consisted of 178 (96 male, 82 female; aged $25-88$ years, mean $56.4 \pm 14.8$ years) hypertensive patients referred to the investigators from the Hypertension Center of The New York Hospital between December 1990 and November 1993. Hypertension was diagnosed as clinically measured pressures $>140 \mathrm{mmHg}$ systolic or $>90 \mathrm{mmHg}$ diastolic, or both, on three determinations over a minimum 2 week period. Isolated systolic hypertension $(\mathrm{SP}>140 \mathrm{mmHg}$ and $\mathrm{DP}<90 \mathrm{mmHg}$ ) was present in 73 patients. All patients were free of antihypertensive medications for at least three weeks. Sixty-five participants had never received antihypertensive medications. Patients with known secondary hypertension, diabetes mellitus, clinical evidence of coronary artery disease (typical angina or 
echocardiographic evidence of myocardial infarction), valvular heart disease as determined by Doppler echocardiography, or cerebrovascular disease (transient ischemic attack or stroke) were excluded from study.

\subsection{Procedures}

Immediately prior to or after the WEP recording, subjects underwent echocardiography, carotid arterial ultrasonography, and applanation tonometry recording in the echocardiography laboratory in the supine position. The study was done in accordance with protocols approved by the Committee on Human Rights in Research, Weill Cornell Medical College. Informed consent was obtained from all study participants.

\subsubsection{WEP Recording}

An "undistorted" WEP signal was recorded with a specially designed foil electret sensor (FES). When coupled to a high impedance $\left(>10^{9} \Omega\right)$ amplifier, the FES has a flat frequency response from below $0.1 \mathrm{~Hz}$ to above $2000 \mathrm{~Hz}$ [11].

Recordings were obtained with the subject in the supine position. After resting for $10 \mathrm{~min}$, a FES was positioned over the brachial artery approximately 1 inch above the antecubital space. A BP cuff with a bladder of recommended width (American Heart Association) was carefully placed such that the distal end of the cuff coincided with the distal end of the FES. The WEP signal was recorded with the CP constant at least $20 \mathrm{mmHg}$ above systolic for at least 3-5 cardiac cycles and as CP was reduced from above systolic to below diastolic. The FES signal was coupled into a Keithley Instruments (Cleveland, OH, USA) electrometer amplifier and a DCV-20/VR6 physiologic recording system (Electronics for Medicine, Pleasantville, NY, USA). Each channel of the VR6 recorder was sampled at $500 \mathrm{~Hz}$ by a 12 bit analog to digital converter for storage into an IBM PC computer using the CODAS (Dataq, Akron, OH, USA) data acquisition software.

To evaluate the K1 pattern, a quantitative measure of the shape of the K1 signal was developed, which is called the "K1 Ratio" (10) (Fig. 2a). Three vectors were defined representing the amplitude from baseline to the first systolic peak (Y1), from baseline to the first trough (Y2) and from baseline to the second systolic peak (Y3).The K1 Ratio was defined as:

$\mathrm{K} 1$ Ratio $=(\mathrm{Y} 1-\mathrm{Y} 2) / \mathrm{Y} 3$.

$(\mathrm{Y} 1-\mathrm{Y} 2)$ was postulated to represent the relative strength of the forward incident pulse wave (Y1) minus the value of $\mathrm{K} 1$ at the initial appearance of wave reflection (Y2) and Y3 was postulated to represent the relative strength of the backward reflected wave. By taking the natural logarithm of the K1 Ratio, we could, in addition to normalizing the distribution of the K1 Ratio, create a variable (K1R) such that the numerical value " 0 " would represent a dividing line $\left(\ln _{\mathrm{e}}(1)=0\right)$.

$\mathrm{K} 1 \mathrm{R}=\ln _{\mathrm{e}}(\mathrm{K} 1$ Ratio $)$

Thus, a negative K1R indicated a stronger reflection component as compared to the incident wave.

All young normotensive individuals so far recorded have exhibited a K1 pattern in which the early systolic peak was larger than the late systolic peak [3-5]. The late systolic peak of $\mathrm{K} 1$ increases with age just as the late systolic peak of the arterial pressure pulse [12] (Fig. 2a, b).

\subsubsection{Echocardiography}

Standard M-mode and two-dimensional echocardiograms were performed using a commercially available echocardiograph with 2.5 and $3.5 \mathrm{MHz}$ imaging transducers. Left ventricular (LV) dimensions were obtained by averaging measurements made from two-dimensionally guided M-mode tracings according to the recommendations of the American Society of Echocardiography $[13,14]$ on up to six cycles with the use of a digitizing tablet. Left ventricular mass (LVM) was calculated using the Penn convention and adjusted for body surface area [15]. Left ventricular geometry was further characterized by LV relative wall thickness (LVRWT) calculated as follows: [ $(2 \times$ posterior wall thickness)/end-diastolic dimension]. LV end-systolic and end-diastolic volumes were calculated according to the Teichholz formula [16] to determine stroke volume (SV). $\mathrm{CO}$ was determined by multiplying the SV by the HR. Total peripheral resistance (TPR) was calculated using the standard formula: [(mean arterial pressure $\times 80) / C O]$. A more detailed description of the echocardiographic methods used has been described [17].

\subsubsection{Carotid Ultrasonography}

This procedure was performed using a Biosound Genesis II system (OTE Biomedica) equipped with a $7.5 \mathrm{MHz}$ probe. With the subject supine and the neck in slight hyperextension, two-dimensionally guided M-mode tracings of the distal common carotid artery (CCA) (approximately $1 \mathrm{~cm}$ proximal to the carotid bulb) were recorded. The simultaneous contralateral carotid pressure tracing was used to time carotid artery measurement at end-diastole and at the time of peak SP. Measurements were performed during several cycles and averaged. Electronic calipers were used to measure the internal diameter (Dd) and far-wall intima-media thickness at end diastole (CIMTd) as well as the diameter at peak systole (Ds). CCA relative wall thickness (CARWT) 
a

TYPICAL K1 PATTERNS:

YOUNG NORMOTENSIVE AND ELDERLY HYPERTENSIVE

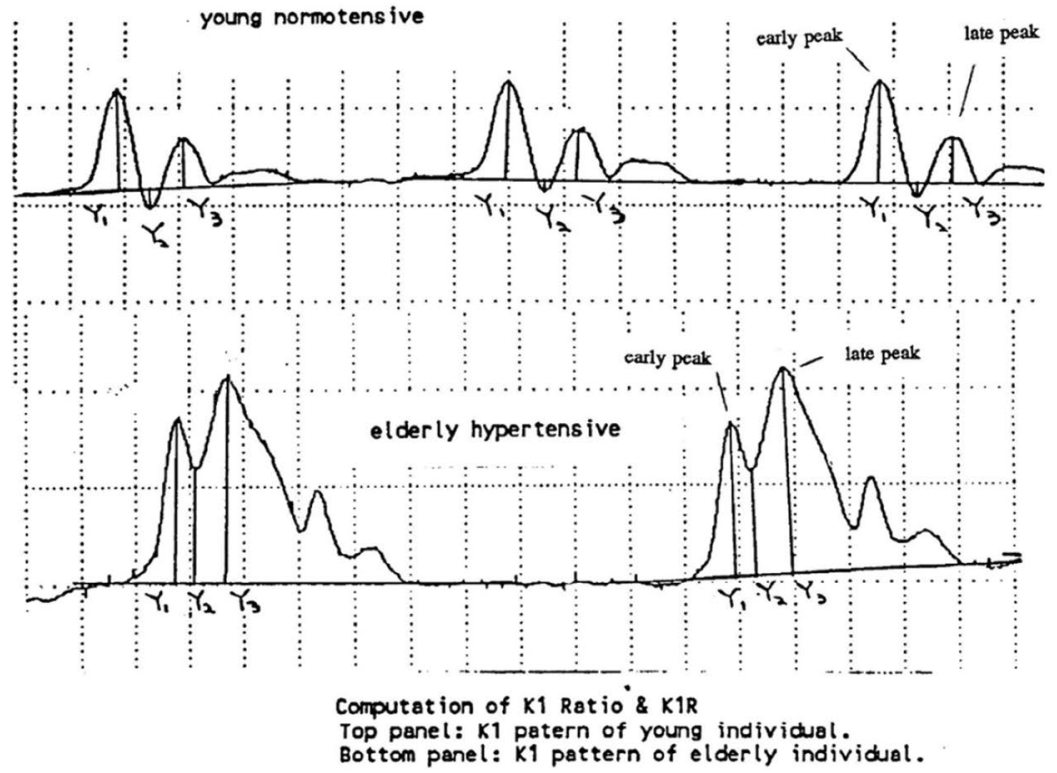

KI Ratio $=\left(Y_{1}-Y_{2}\right) / Y_{3}$

$K 1 R=1 n_{e}(K 1$ Ratio)

b

MURGO: TYPE C

MURGO: TYPEA

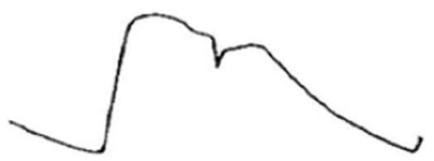

AORT:C PRESSURE

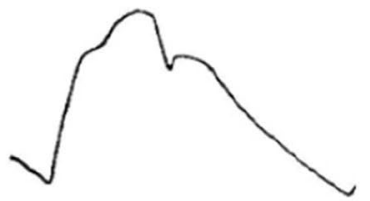

YOUNG NORMOTENSIVE

ELDERLY HYPERIENSIVE

WEP K1 PAITERN
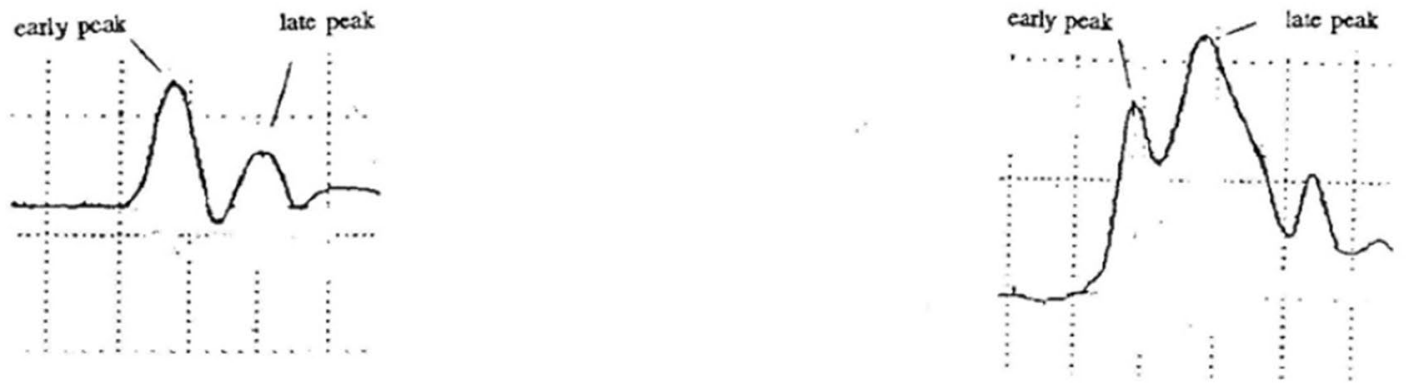
४Fig. 2 a Typical K1 Patterns. Top Panel: K1 pattern of young normotensive individual. Bottom Panel: K1 pattern of elderly hypertensive individual. Computation of "K1 Ratio" and "K1R": K1 Ratio $=(\mathrm{Y} 1-\mathrm{Y} 2) / \mathrm{Y} 3, \mathrm{~K} 1 \mathrm{R}=\ln$ e $(\mathrm{K} 1$ Ratio). b Corresponding K1 patterns and Aortic Pressure Waveforms (according to Murgo et al. [12]. Top row: Aortic pressure waves Bottom row: WEP K1 patterns. Left panel: Murgo Type $\mathrm{C}$ aortic pressure wave corresponding to the WEP K1 pattern where the late systolic peak is less than the early systolic peak $(\mathrm{K} 1 \mathrm{R}>0)$. Right panel: Murgo Type A pressure wave corresponding to the WEP K1 pattern where the late systolic peak is greater than the early systolic peak $(\mathrm{K} 1 \mathrm{R}<0)$

at end-diastole was calculated as follows: $[(2 \times$ CIMTd $) /$ Dd]. Carotid artery stiffness was evaluated by $\beta$ as follows: $\beta=[\operatorname{Ln}(\mathrm{Ps} / \mathrm{Pd})] /[(\mathrm{Ds}-\mathrm{Dd}) / \mathrm{Dd}]$, where Ps and Pd are SP and DP respectively $[18,19]$. Arterial compliance (AC) was determined by the SV divided by PP. Cross-sectional area (CSA) was used as a measure of carotid artery wall mass and was computed as: $\mathrm{CSA}=\pi \times[\mathrm{CIMTd}+(\mathrm{Dd} / 2)]^{2}-\pi \times$ $\left[(\mathrm{Dd} / 2)^{2}\right]$. Both carotid arteries were scanned to identify the presence and size of atherosclerotic plaques. A more detailed description of the carotid artery ultrasonography procedure has been described [17].

\subsubsection{Carotid Pressure Waveforms}

Tonometric carotid artery pressure wave forms were recorded using a high fidelity Millar Instruments external pressure transducer (Model SPT-301) positioned over a common carotid artery with the subject in the supine position. The technique used in this study has been described in full [17]. Applanation tonometry recordings obtained from the carotid artery in this manner have been shown to closely resemble intra-arterial ascending aortic pressure waveforms $[12,20]$. Carotid pressure waveforms were analyzed to determine the augmentation index (AIx) in 123 subjects.

\subsection{Statistical Analysis}

Relationships between K1R and age, weight, height, the cardiovascular systemic functions, and measures of left ventricular and carotid structure were examined using Pearson correlations, bivariate regressions and one-way ANOVAs [using dichotomized K1R groupings (< or $>0)$ ]. Stepwise regression analysis was undertaken to further evaluate the independence of the parameter relationships with K1R. The potential predictors of $\mathrm{K} 1 \mathrm{R}$ included in this procedure were: age, gender, height, weight, SP, (using K2 algorithm), HR, TPR, CO, stiffness index ( $\beta$ ), arterial compliance (SV/ PP), LVM, LVM index, LVRWT, aortic diameter, CARWT, CIMTd, presence of carotid plaque, and CSA. Collinearity among the retained parameters was evaluated using the Variance Inflation Factor (VIF). Values less than 2 would indicate low collinearity. A logistic regression analysis using the Forward Wald procedure was conducted to determine the best predictors of a negative K1R. The variables tested were the same variables used in the linear stepwise regression.

Because CARWT and left ventricular geometry (e.g. LVM) are likely a result rather than a cause of the pressure pulse, stepwise analyses were conducted to clarify their relationships with K1R in which CARWT and measures of LVM were evaluated as dependent variables. These analyses included K1R, age, gender height, weight, TPR, SP, $\mathrm{PP}$ and HR as predictors. The F to enter in the stepwise models was set at $3.84(\mathrm{p}<0.05)$ and the $\mathrm{F}$ to remove was $2.71(\mathrm{p}<0.10)$. Relationships were considered statistically significant at $\mathrm{p}<0.05$. Analyses were conducted using SPSS 21 for Windows.

\section{Results}

Anthropometric, functional, and structural means and correlations with K1R are shown in Table 1. The strongest overall correlation was the inverse relationship with age (Fig. 3). $\mathrm{K} 1 \mathrm{R}$ was positively associated with height, weight, and body surface area, inversely related to SP, PP, MP, TPR, and $\beta$ and directly related to $\mathrm{CO}, \mathrm{HR}$, and $\mathrm{AC}$. There was a direct correlation with LVM and inverse correlations with LVRWT, CARWT, $\mathrm{CIMT}_{\mathrm{d}}$, and CSA.

ANOVA revealed that the $\mathrm{K} 1 \mathrm{R}<0$ group was, on average, older and shorter, had lower weight and body surface area, and a greater proportion of females than the K1R $>0$ group. Hemodynamically, K1R $<0$ had on average, higher SP, PP, and MP, lower HR, greater TPR, lower CO, a stiffer arterial system, and reduced $\mathrm{AC}$; they also had, on average, lower LVM, and greater LVRWT, CARWT, CIMTd, and CSA. Finally, K1R $<0$ had a greater incidence of CA plaque; thirty out of 87 had plaque in this group versus 6 out of 54 in $\mathrm{K} 1 \mathrm{R}>0(\mathrm{p}=0.004)$. However, the statistical significance of this finding disappeared when adjusted for age (Table 2).

Stepwise regression revealed that independent and additive correlates of K1R included age, TPR, SP, gender, and HR (Table 3). Although K1R was strongly correlated with $\beta$ and the presence of CA plaque, the associations are no longer significant when age and TPR were included in the analysis. Importantly, the VIF for all the variables retained was less than 1.5 , indicating low collinearity among them.

Stepwise logistic regression showed that the model reliably distinguished between K1R $>$ or $<0(\mathrm{p}<0.0001)$ with Nagelkerke's $\mathrm{R}^{2}$ of 0.773 indicating a moderately strong relationship. Prediction success overall was $89.3 \%$ (92.2\% for $\mathrm{K} 1 \mathrm{R}<0$ and $84.4 \%$ for $\mathrm{K} 1 \mathrm{R}>0$ ). The model indicated that every year increase in age increased the odds of having a negative K1R by $17.3 \%(\mathrm{p}<0.001)$; every unit increase in TPR increased the odds of having a negative K1R by $0.2 \%$ ( $\mathrm{p}<0.052)$; every $\mathrm{mmHg}$ increase in SP increase the odds 
Table 1 Parameter means and correlations with K1R

\begin{tabular}{|c|c|c|c|c|}
\hline & $\mathrm{N}$ & Mean (SD) & Correlation w/K1R (N) & $\mathrm{p}$ value \\
\hline \multicolumn{5}{|c|}{ Anthropometry/Demographics } \\
\hline Age (years) & 178 & $56.8(14.5)$ & $-0.600(170)$ & 0.0001 \\
\hline Height (m) & 161 & $1.69(0.10)$ & $0.408(154)$ & 0.0001 \\
\hline Weight (kg) & 161 & $74.0(15.2)$ & $0.408 .(154)$ & 0.0001 \\
\hline Body surface area $\left(\mathrm{m}^{2}\right)$ & 162 & $1.84(0.22)$ & $0.432(154)$ & 0.0001 \\
\hline Gender ( $\%$ male $)$ & 94 & $(55.3)$ & - & - \\
\hline (\% female) & 76 & $(44.7)$ & & \\
\hline \multicolumn{5}{|l|}{ Systemic Functions } \\
\hline K1R & 170 & $-0.245(0.91)$ & - & - \\
\hline Augmentation Index (\%) & 123 & $14.4(12.0)$ & $-0.523(122)$ & 0.0001 \\
\hline Systolic pressure (mmHg) & 176 & $151(24.5)$ & $-0.416(168)$ & 0.0001 \\
\hline Diastolic pressure $(\mathrm{mmHg})$ & 176 & $83(12.0)$ & $-0.150(168)$ & 0.052 \\
\hline Pulse pressure $(\mathrm{mmHg})$ & 176 & $68(19.0)$ & $-0.453(168)$ & 0.0001 \\
\hline Mean pressure (mmHg) & 176 & $105(14.9)$ & $-0.307(168)$ & 0.0001 \\
\hline Heart rate (bpm) & 178 & $68(12)$ & $0.261(170)$ & 0.001 \\
\hline TPR (dyn s cm ${ }^{-5}$ ) & 161 & $1739(473)$ & $-0.434(154)$ & 0.0001 \\
\hline Cardiac output (1/min) & 161 & $5.27(1.41)$ & $0.306(154)$ & 0.0001 \\
\hline Stiffness $(\beta)$ & 141 & $6.19(3.71)$ & $-0.337(138)$ & 0.0001 \\
\hline Compliance (ml/mmHg) & 159 & $1.33(0.44)$ & $0.456(152)$ & 0.0001 \\
\hline \multicolumn{5}{|l|}{ LV Structure } \\
\hline LV mass (g) & 159 & $164(45)$ & $0.161(152)$ & 0.05 \\
\hline LVRWT & 159 & $0.365(0.055)$ & $-0.253(152)$ & 0.01 \\
\hline \multicolumn{5}{|l|}{ Vascular Variables } \\
\hline Aortic diameter $(\mathrm{cm})$ & 160 & $3.28(0.40)$ & $0.036(153)$ & 0.660 \\
\hline CARWT & 159 & $0.286(0.072)$ & $-0.314(152)$ & 0.0001 \\
\hline CIMTd (mm) & 160 & $0.822(0.20)$ & $-0.336(153)$ & 0.0001 \\
\hline $\operatorname{CSA}\left(\mathrm{mm}^{2}\right)$ & 159 & $17.2(5.8)$ & $-0.287(152)$ & 0.001 \\
\hline
\end{tabular}

$T P R$ Total Peripheral Resistance, $L V R W T$ LV relative wall thickness, CARWT carotid artery relative wall thickness, CIMTd carotid artery far wall intima-media thickness-diastole, CSA carotid artery cross-sectional area (surrogate for CA wall mass)

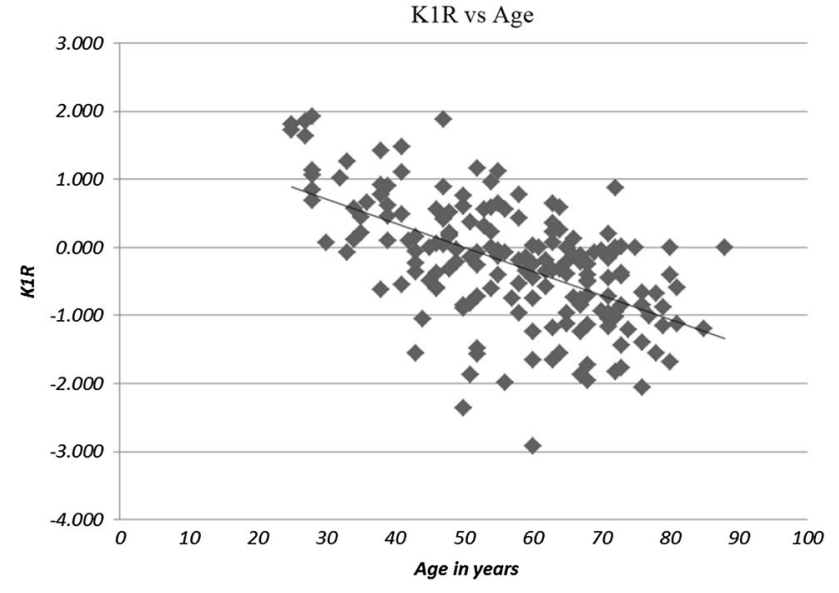

Fig. 3 Plot of "K1R vs Age" (with corresponding regression equation). $\mathrm{K} 1 \mathrm{R}=1.771-0.0353 \times$ age $\left(\mathrm{R}^{2}=0.33\right)$

of having a negative K1R by $8.7 \%(\mathrm{p}<0.001)$; every $\mathrm{mm}$ increase in aortic diameter decreased the odds of having a negative K1R by $92.9 \%(\mathrm{p}<0.015)$ and finally every $\mathrm{kg}$ increase in weight decreases the odds of having a negative K1R by $8.1 \%(\mathrm{p}<0.005)$ (Table 4$)$.

The CARWT analysis showed that PP and K1R were independent and additive correlates of CARWT (Table 5). Age did not enter into the model. Finally, the analysis examining the correlates of LVM or LVRWT revealed that K1R was not an independent correlate of either (not shown).

\section{Discussion}

\subsection{Relationship of the WEP K1 Signal to the Arterial Pressure}

When the cuff pressure is above systolic for the entire cardiac cycle, pulse wave penetration through the occluded artery is incomplete. The primary dynamic force responsible for the $\mathrm{K} 1$ pattern is the impact of the propagating intra-arterial 
Table 2 K1R group comparisons of the anthropometric functional and structural measures

\begin{tabular}{|c|c|c|c|c|c|}
\hline & \multicolumn{2}{|c|}{$\mathrm{K} 1 \mathrm{R}>0$} & \multirow[t]{2}{*}{$\mathrm{p}$ value } & \multicolumn{2}{|c|}{$\mathrm{K} 1 \mathrm{R}<0$} \\
\hline & $\mathrm{N}$ & Mean (SD) & & $\mathrm{N}$ & Mean (SD) \\
\hline \multicolumn{6}{|l|}{ Subject Characteristics } \\
\hline Age (years) & 64 & $45.9(12.8)$ & 0.0001 & 106 & $62.6(11.2)$ \\
\hline Height (m) & 57 & $1.74(0.10)$ & 0.0001 & 97 & $1.66(0.09)$ \\
\hline Weight $(\mathrm{kg})$ & 57 & $82.7(15.4)$ & 0.0001 & 97 & $69.5(12.7)$ \\
\hline Body surface area $\left(\mathrm{m}^{2}\right)$ & 59 & $1.97(0.217)$ & 0.0001 & 97 & $1.78(0.190)$ \\
\hline Gender $(\% \text { Male })^{\mathrm{a}}$ & 49 & $(76.6)$ & 0.0001 & 45 & $(42.5)$ \\
\hline (\% Female $)$ & 15 & $(23.4)$ & & 61 & $(57.5)$ \\
\hline \multicolumn{6}{|l|}{ Systemic Function } \\
\hline Augmentation Index (\%) & 49 & $8.5(14.6)$ & 0.0001 & 73 & $18.4(8.7)$ \\
\hline Systolic pressure (mmHg) & 54 & $140(19.4)$ & 0.0001 & 104 & $158(24.7)$ \\
\hline Diastolic pressure $(\mathrm{mmHg})$ & 54 & $81(12.8)$ & 0.13 & 104 & $84(12.0)$ \\
\hline Pulse pressure (mmHg) & 54 & $59(11.4)$ & 0.0001 & 104 & $74(19.4)$ \\
\hline Mean pressure (mmHg) & 54 & $101(14.3)$ & 0.01 & 104 & $109(14.7)$ \\
\hline Heart rate $(\mathrm{bpm})$ & 56 & $71(11.7)$ & 0.01 & 106 & $66(10.8)$ \\
\hline TPR (dyn s cm $\mathrm{cm}^{-5}$ ) & 59 & $1496(387)$ & 0.0001 & 95 & $1882(457)$ \\
\hline Cardiac output (1/min) & 59 & $5.90(1.34)$ & 0.0001 & 95 & $5.09(1.33)$ \\
\hline Stiffness $(\beta)$ & 51 & $4.61(2.28)$ & 0.0001 & 87 & $7.20(4.08)$ \\
\hline Compliance $(\mathrm{ml} / \mathrm{mmHg})$ & 58 & $1.61(0.440)$ & 0.0001 & 94 & $1.18(0.351)$ \\
\hline \multicolumn{6}{|l|}{ LV Structure } \\
\hline LV mass (g) & 58 & $174(52.1)$ & 0.05 & 94 & $159(40.8)$ \\
\hline LVRWT & 58 & $346(0.059)$ & 0.001 & 94 & $0.375(0.048)$ \\
\hline \multicolumn{6}{|l|}{ Vascular Variables } \\
\hline Aortic diameter $(\mathrm{cm})$ & 58 & $3.32(0.40)$ & 0.38 & 95 & $3.26(0.40)$ \\
\hline CARWT & 59 & $0.257(0.055)$ & 0.0001 & 93 & $0.297(0.070)$ \\
\hline CIMTd (mm) & 59 & $0.727(0.159)$ & 0.0001 & 94 & $0.869(0.195)$ \\
\hline $\operatorname{CSA}\left(\mathrm{mm}^{2}\right)$ & 59 & $14.9(4.7)$ & 0.0001 & 93 & $18.7(5.9)$ \\
\hline
\end{tabular}

$T P R$ total peripheral resistance, $L V R W T$ LV relative wall thickness, CARWT carotid artery relative wall thickness, CIMTd carotid artery far wall intima-media thickness-diastole, CSA carotid artery cross-sectional area (surrogate for CA wall mass)

aproportional comparisons Male/Female by Chi-Square analysis
Table 3 Final regression model of correlates of K1R $(\mathrm{N}=122)$

\begin{tabular}{lcll}
\hline Model parameter & $\begin{array}{l}\text { Standardized } \beta \\
\text { coefficient }\end{array}$ & $\mathrm{p}$ value & Incremental $\mathrm{R}^{2}$ \\
\hline Age & -0.510 & 0.0001 & 0.441 \\
TPR $^{\mathrm{b}}$ & -0.151 & 0.009 & 0.095 \\
Systolic pressure $^{\mathrm{a}}$ & -0.517 & 0.0001 & 0.053 \\
Gender $_{\text {Heart rate }}^{\mathrm{a}}$ & 0.267 & 0.0001 & 0.030 \\
& 0.212 & 0.007 & 0.023
\end{tabular}

Total $\mathrm{R}^{2}=0.64$ (Model: $\mathrm{p}<0.0001$ )

The potential predictors of K1R included in these procedures were: age, gender, height, weight, SP (as determined from the K2 algorithm), HR, TPR, CO, stiffness index $(\beta)$, arterial compliance (SV/ PP), LVM, LVM index, LVRWT, aortic diameter, CARWT, CIMTd, presence of carotid plaque, and CSA (surrogate for Vascular Mass)

${ }^{a}$ Measured using the K2 Algorithm from the WEP signal

${ }^{\mathrm{b}}$ Total peripheral resistance (TPR)
Table 4 Final logistic model of predictors of negative K1R $(\mathrm{N}=122)$

\begin{tabular}{lclll}
\hline Model parameter & $\beta$ coefficient & $\mathrm{p}$ value & Odds ratio & $95 \% \mathrm{CI}$ \\
\hline Age & 0.16 & 0.0001 & 1.173 & $1.090-1.263$ \\
TPR $^{\mathrm{b}}$ & 0.002 & 0.05 & 1.002 & $1.000-1.004$ \\
Systolic pressure $^{\mathrm{a}}$ & 0.084 & 0.001 & 1.087 & $1.035-1.142$ \\
Aortic diameter $^{\text {Weight }}$ & -2.638 & 0.02 & 0.071 & $0.009-0.598$ \\
& -0.084 & 0.005 & 0.919 & $0.867-0.974$ \\
\hline
\end{tabular}

Nagelkerke $\mathrm{R}^{2}=0.77$ (Model: $\mathrm{p}<0.0001$ )

The potential predictors of K1R included in these procedures were: age, gender, height, weight, SP (as determined from the K2 algorithm), HR, TPR, CO, stiffness index ( $\beta$ ), arterial compliance (SV/ PP), LVM, LVM index, LVRWT, aortic diameter, CARWT, CIMTd, presence of carotid plaque, and CSA (surrogate for Vascular Mass)

${ }^{\text {a }}$ Measured using the K2 Algorithm from the WEP signal

${ }^{\mathrm{b}}$ Total peripheral resistance (TPR) 
Table 5 Final regression model of correlates of carotid artery relative wall thickness $(\mathrm{N}=139)$

\begin{tabular}{lcll}
\hline Model parameter & $\begin{array}{l}\text { Standardized } \beta \\
\text { coefficient }\end{array}$ & p value & Incremental $\mathrm{R}^{2}$ \\
\hline Pulse pressure $^{\mathrm{a}}$ & 0.249 & 0.001 & 0.114 \\
K1R & -0.191 & 0.04 & 0.029 \\
\hline
\end{tabular}

Total $\mathrm{R}^{2}=0.14(\mathrm{p}<0.0001)$

This analysis included K1R, age, gender height, weight, TPR, SP, PP, and $\mathrm{HR}$ as predictors

${ }^{\text {a }}$ Measured using the $\mathrm{K} 2$ Algorithm from the WEP signal

pressure pulse against the occluded brachial artery. The K1 signal is not affected by the local pulse wave reflection of the arm and hand and is more representative of a central arterial pressure pulse. Payne et al. [21] have demonstrated an intrinsic relationship between the suprasystolic WEP pattern (i.e., $\mathrm{K} 1$ ) and the first derivative of an intra-arterial pressure wave. The K1 pattern has 2 identifiable systolic peaks separated by an identifiable trough. This is in contrast to the difficulty of identifying the timing of the so-called "fiducial" point in the determination of the augmentation index [22].

\subsection{K1R and Age}

An accelerated aging process results in atherosclerosis, hypertension and stroke [23]. Studies have demonstrated a strong relationship between the shape of the arterial pressure pulse with age [24]. We found K1R has a strong inverse and independent correlation with age $(\mathrm{r}=-0.60, \mathrm{p}<0.0001$; Table 3). Thus, K1R may represent a simple and sensitive marker for arterial vascular aging.

\subsection{K1R and Functional Properties}

There is a strong correlation of $\mathrm{K} 1 \mathrm{R}$ with the CA derived AIx $(r=-0.523, p<0.0001)$. K1R also has inverse relationships with SP, PP and MP, TPR, $\beta$ and a direct correlation with $\mathrm{CO}$ and $\mathrm{AC}$. When K1R was dichotomized (< or $>0$ ), $\mathrm{K} 1 \mathrm{R}<0$ was associated with higher SP, PP and MP, an increased $\beta$, and a reduced $\mathrm{CO}$ and $\mathrm{HR}$. These relationships are consistent with the hemodynamic changes expected with aging and hypertension development.

\subsection{K1R and Vascular Tone}

The shape of the propagating arterial pressure pulse is affected by the timing and amount of pulse wave reflection [25]. Consistent with this principle, we found that K1R was independently related to TPR. Thus, the K1 pattern can be thought of as an integrating factor related to the timing and level of reflected waves (degree of constriction of small muscular arteries and arterioles, peripheral resistance). We have previously demonstrated changes in the $\mathrm{K} 1$ pattern with changes in vasomotor tone [26, 27]. K1R could be a useful clinical tool in evaluating early malfunctional vascular changes that may occur in the initial stages of preeclampsia [26].

\subsection{K1R and Cardiovascular Structure}

Results indicate PP and K1R are independent and additive correlates of CARWT. Since thickening and dilation of large proximal arteries and endothelial dysfunction are associated with aging and an increased late systolic peak in the central arterial pressure [17], it was expected that CARWT would be greater in $\mathrm{K} 1 \mathrm{R}<0$. This was the case. We also found that CSA and CIMTd was greater in $\mathrm{K} 1 \mathrm{R}<0$ and that $\mathrm{K} 1 \mathrm{R}<0$ had an age associated greater incidence of carotid artery plaque. The increased wall thickness is compatible with a greater degree of atherosclerosis. Increased carotid artery wall thickness is a risk factor for coronary related death and fatal stroke [28].

Finally, while patients with $\mathrm{K} 1 \mathrm{R}<0$ had an increased LVRWT, K1R was not independently associated with either LVM or LVRWT, which may suggest that wave reflection back to the upper limb is too far removed from the left ventricle.

\subsection{Functional and Structural Determinants of the K1 Pattern}

The regression and logistic models revealed that age, TPR, and SP were common independent determinants of K1R. The logistic model also showed that aortic diameter was an independent predictor of K1R.. The model suggests that every $\mathrm{mm}$ increase in diameter decreases the odds of having a negative K1R by $92.9 \%$. This result is consistent with recent reports that have claimed that an increased PP in systolic hypertension is primarily due to an increased arterial stiffness and a reduced aortic diameter [29].

\subsection{Limitations of Study}

The cross-sectional nature and small sample size of the study limits the generalizability of our findings. Furthermore, while patients with known secondary hypertension were excluded, we did not specifically screen for them. While K1R is derived from a relatively central pressure wave, it is not equivalent to the ascending aortic wave. Finally, gender issues were not evaluated in the analysis, which might affect the results.

\section{Conclusions}

$\mathrm{K} 1 \mathrm{R}$ is related to functional and perhaps structural properties of the vascular system. K1R may represent a simple and sensitive marker for arterial vascular aging and may also be a 
useful tool in evaluating clinically relevant vascular changes (e.g., preeclampsia). Because it is independently related to peripheral resistance, noninvasive WEP K1 analysis may help in identifying both "the need for" and "the effectiveness of" hypertension treatment. Finally, because K1R is derived from a part of the same WEP signal used to accurately measure blood pressure (K2 Analysis), it is possible that characterization of cardiovascular function and evaluation of cardiovascular risk could be accomplished from a single cuff deflation procedure.

\section{Compliance with Ethical Standards}

Conflict of interest The authors declare that they have no conflict of interest.

Ethical approval All procedures performed in studies involving human participants were in accordance with the ethical standards of the institutional and/or national research committee and with the Helsinki declaration and its later amendments or comparable ethical standards. Approved by Committee on Human Rights in Research, Weill Cornell Medical College.

Informed consent Informed consent was obtained from all individual participants included in the study.

Open Access This article is distributed under the terms of the Creative Commons Attribution-NonCommercial 4.0 International License (http://creativecommons.org/licenses/by-nc/4.0/), which permits any noncommercial use, distribution, and reproduction in any medium, provided you give appropriate credit to the original author(s) and the source, provide a link to the Creative Commons license, and indicate if changes were made.

\section{References}

1. Avolio AP, Butlin M, Walsh A. Arterial blood pressure measurement and pulse wave analysis - their role in enhancing cardiovascular assessment. Physiol Meas. 2010;31:R1-47.

2. Avolio AP, Van Bortel LM, Boutouyrie P, Cockcroft JR, McEniery CM, Protogerou AD, Roman MJ, Safar ME, Segers $\mathrm{P}$, Smulyan $\mathrm{H}$. Role of pulse pressure amplification in Arterial Hypertension: experts opinion and review of the data. Hypertension. 2009;54:375-83.

3. Blank SG, West JE, Muller FB, Cody RJ, Harshfield GA, Pecker MS, Laragh JH, Pickering TG. Wideband external pulse recording during cuff deflation: a new technique for evaluation of the arterial pressure pulse and measurement of blood pressure. Circulation. 1988;77(6):1297-305.

4. Denby L, Mallows CL, Blank SG. Analysis of the wideband external pulse: an application of graphical methods. Stat Med. 1994;13:275-91.

5. Blank SG, West JE, Muller FB, Pecker MS, Laragh JH, Pickering TG. Characterization of auscultatory gaps with wideband external pulse recording. Hypertension. 1991;17:225-33.

6. Blank SG, Helseth G, Pickering TG, West JE, August P. How should diastolic blood pressure be defined during pregnancy? Hypertension. 1994;24:234-40.

7. Blank SG, Mann SJ, James GD, West JE, Pickering TG. Isolated elevation of diastolic blood pressure: real or artifactual? Hypertension. 1995;26:383-9.
8. Cavallini MC, Roman MJ, Blank SG, Pini R, Pickering TG, Devereux RB. Association of the auscultatory gap with vascular disease in hypertensive patients. Ann Intern Med. 1996;124:877-83.

9. Blank SG. The Korotkoff signal and its relationship to the arterial pressure pulse. Ph.D. thesis, Cornell University Graduate School of Medical Sciences, 1987.

10. Blank SG, Wideband External Pulse Cardiac Monitor. US Patent 5913826, 1996.

11. West JE, Busch-Vischniac IJ, Harshfield GA, Pickering TG. Foil electret transducer for blood pressure monitoring. J Acoust Soc Am. 1983;74:680.

12. Murgo JP, Westerhoff N, Giolma JP, Altobelli SA. Aortic input impedance in normal man: relationship to pressure waveforms. Circulation. 1980;62:105-16.

13. Sahn DJ, DeMaria A, Kisslo J, Weyman A. Recommendation regarding quantitation in M-mode echocardiography: results of a survey of echocardiographic measurements. Circulation. 1978;58:1072-83.

14. Schiller NB, Shah PM, Crawford M, et al. Recommendation for quantitation of the left ventricle by two-dimensional echocardiography. J Am Soc Echocardiography. 1989;2:358-67.

15. Devereux RB, Reichek N. Echocardiographic determination of left ventricular mass in man. Anatomic validation of the method. Circulation. 1977;55:613-8.

16. Teichholz LE, Kreulen T, Herman MV, Gorlin R. Problems in echocardiographic-angiographic correlations in the presence or absence of asynergy. Am J Cardiol. 1976;37:7-11.

17. Saba PS, Roman MJ, Pini R, Spitzer M, Ganau A, Devereux $\mathrm{RB}$. Relation of arterial pressure waveform to left ventricular and carotid anatomy in normotensive subjects. JACC. 1993;22:1873-80.

18. Hayashi K, Handa H, Nagasawa S, Okumura A, Moritaki K. Stiffness and elastic behavior of human intracranial and extracranial arteries. J Biomech. 1980;13:175-84.

19. Hirai T, Sasayma S, Kawasaki T, Yagi S. Stiffness of systemic arteries in patients with myocardial infarction: a noninvasive method to predict severity of coronary atherosclerosis. Circulation. 1989;80:78-86.

20. Kelly R, Karamanoglu M, Gibbs H, Avolio A, O'Rourke MF. Noninvasive carotid pressure wave registration as an indicator of ascending aortic pressure. J Vasc Med Biol. 1989;1:241-7.

21. Payne RA, Isnardi D, Andrews PJD, Maxwell SRJ, Webb DJ. Similarity between the suprasystolic wideband external pulse wave and the first derivative of the intra-arterial pulse wave. $\mathrm{Br} \mathrm{J}$ Anesth. 2007;99(5):653-61.

22. Segers P, Kips J, Trachet B, Swillens A, Vermeersch S, Mahieu D, Rietzschel E, De Buyzere M, Van Bortel L. Limitations and pitfalls of non-invasive measurement of arterial pressure wave reflections and pulse wave velocity. Artery Res. 2009;3:79-88.

23. Lakatta EG, Levy D. Arterial and cardiac aging: major shareholders in cardiovascular disease enterprises: part I: aging arteries: a "set up" for vascular disease. Circulation. 2003;107:139-46.

24. Kelly R, Hayward C, Avolio A, O'Rourke M. Noninvasive determination of age-related changes in the human arterial pulse. Circulation. 1989;80:1652-9.

25. Kelly RP, Millasseau SC, Ritter PJ, Chowienczyk PJ. Vasoactive drugs influence aortic augmentation index independently of pulse wave velocity. Hypertension. 2001;37:1429-33.

26. Blank SG, Helseth GM, August P. Systemic vascular tone in normotensive and hypertensive pregnancies: sequential assessment with a new noninvasive technique. Hypertens Pregnancy. 1993;12(2):224.

27. Blank SG, Bading B, Sharrock NE, Pickering TG. The wideband external pulse and vasomotor tone in an elderly population. Am J Hypertens. 1993;6(5):38A. 
28. Go AS, Mozaffarian D, Roger VL, Benjamin EJ, et al. Heart disease and stroke statistics-2013 update. A report from the Am. Heart association statistics committee and stroke statistics subcommitte. Circulation. 2013;127:e6-245.
29. Mitchell GF, Conlin PR, Dunlap ME, Lacourciere Y, Malcolm J, Arnold O, Ogilvie RI, Neutel J, Izzo JL, Pfeffer MA. Aortic diameter, wall stiffness and wave reflection in systolic hypertension. Hypertension. 2008;51:105-11. 